OPEN ACCESS

Edited by:

Luigi Camporota,

Guy's and St Thomas' NHS

Foundation Trust, United Kingdom

Reviewed by:

Elena Spinelli,

IRCCS Ca 'Granda Foundation Maggiore Policlinico Hospital, Italy

Lise Piquilloud,

Centre Hospitalier Universitaire

Vaudois (CHUV), Switzerland

*Correspondence:

Lorenzo Ball

Iorenzo.ball@unige.it

tThese authors share senior authorship

Specialty section:

This article was submitted to Respiratory Physiology, a section of the journal

Frontiers in Physiology

Received: 15 June 2021 Accepted: 17 September 2021 Published: 22 October 2021

Citation:

Ball $L$, Sutherasan $Y$, Fiorito $M$ Dall'Orto A, Maiello L, Vargas M,

Robba C, Brunetti I, D'Antini D, Raimondo P, Huhle R, Schultz MJ,

Rocco PRM, Gama de Abreu M and

Pelosi P (2021) Effects of Different

Levels of Variability and Pressure

Support Ventilation on Lung Function in Patients With Mild-Moderate Acute

Respiratory Distress Syndrome.

Front. Physiol. 12:725738. doi: 10.3389/fphys.2021.725738

\section{Effects of Different Levels of Variability and Pressure Support Ventilation on Lung Function in Patients With Mild-Moderate Acute Respiratory Distress Syndrome}

\author{
Lorenzo Ball $^{1,2 *}$, Yuda Sutherasan ${ }^{3}$, Martina Fiorito ${ }^{1}$, Antonella Dall'Orto ${ }^{1,}$ \\ Lorenzo Maiello $^{1}$, Maria Vargas ${ }^{4}$, Chiara Robba ${ }^{1,2}$, lole Brunetti ${ }^{2}$, Davide D’Antini ${ }^{1,5}$, \\ Pasquale Raimondo ${ }^{1,5}$, Robert Huhle ${ }^{6}$, Marcus J. Schultz ${ }^{6,7,8+}$, Patricia R. M. Rocco ${ }^{9 \dagger}$, \\ Marcelo Gama de Abreu ${ }^{10 \dagger}$ and Paolo Pelosi ${ }^{1,2 \dagger}$
}

\begin{abstract}
'Department of Surgical Sciences and Integrated Diagnostics, University of Genoa, Genoa, Italy, ${ }^{2}$ Anesthesia and Intensive Care, Ospedale Policlinico San Martino Istituto di Ricerca e Cura a Carattere Scientifico (IRCCS) for Oncology and Neurosciences, Genova, Italy, ${ }^{3}$ Division of Pulmonary and Pulmonary Critical Care Medicine, Department of Medicine, Ramathibodi Hospital, Mahidol University, Bangkok, Thailand, ${ }^{4}$ Department of Neurosciences, Reproductive and Odonthostomatological Sciences, University of Naples Federico II, Naples, Italy, ${ }^{5}$ Department of Anaesthesia and Intensive Care, University of Foggia, Foggia, Italy, ${ }^{6}$ Mahidol Oxford Tropical Medicine Research Unit (MORU), Mahidol University, Bangkok, Thailand, ${ }^{7}$ Department of Intensive Care, Laboratory of Experimental Intensive Care and Anesthesiology (LEICA), Amsterdam University Medical Centers, Location Academic Medical Center (AMC), Amsterdam, Netherlands, ${ }^{8}$ Nuffield Department of Medicine, Oxford University, Oxford, United Kingdom, ${ }^{9}$ Laboratory of Pulmonary Investigation, Carlos Chagas Filho Institute of Biophysics, Federal University of Rio de Janeiro, Rio de Janeiro, Brazil, ${ }^{10}$ Pulmonary Engineering Group, Department of Anaesthesiology and Intensive Care Medicine, University Hospital Carl Gustav Carus, Technische Universität Dresden, Dresden, Germany
\end{abstract}

Background: Variable pressure support ventilation (vPSV) is an assisted ventilation mode that varies the level of pressure support on a breath-by-breath basis to restore the physiological variability of breathing activity. We aimed to compare the effects of VPSV at different levels of variability and pressure support $\left(\Delta P_{S}\right)$ in patients with acute respiratory distress syndrome (ARDS).

Methods: This study was a crossover randomized clinical trial. We included patients with mild to moderate ARDS already ventilated in conventional pressure support ventilation (PSV). The study consisted of two blocks of interventions, and variability during vPSV was set as the coefficient of variation of the $\Delta P_{S}$ level. In the first block, the effects of three levels of variability were tested at constant $\Delta P_{S}$ : $0 \%$ (PSV $0 \%$, conventional PSV), $15 \%$ $\left(\mathrm{vPSV}_{15 \%}\right)$, and $30 \%\left(\mathrm{VPSV}_{30 \%}\right)$. In the second block, two levels of variability (0\% and variability set to achieve $\pm 5 \mathrm{cmH}_{2} \mathrm{O}$ variability) were tested at two $\Delta \mathrm{P}_{\mathrm{S}}$ levels (baseline $\Delta P_{S}$ and $\Delta P_{S}$ reduced by $5 \mathrm{cmH}_{2} \mathrm{O}$ from baseline). The following four ventilation strategies were tested in the second block: PSV with baseline $\Delta P_{S}$ and $0 \%$ variability ( $P S V_{\mathrm{BL}}$ ) or $\pm 5 \mathrm{cmH}_{2} \mathrm{O}$ variability ( $\mathrm{VPSV} \mathrm{BL}_{\mathrm{BL}}$ ), $\mathrm{PSV}$ with $\Delta \mathrm{P}_{\mathrm{S}}$ reduced by $5 \mathrm{cmH}_{2} \mathrm{O}$ and $0 \%$ variability $\left(\mathrm{PSV}_{-5}\right.$ ) or $\pm 5 \mathrm{cmH}_{2} \mathrm{O}$ variability ( $\left(\mathrm{VSV}_{-5}\right)$. Outcomes included gas exchange, respiratory mechanics, and patient-ventilator asynchronies.

Results: The study enrolled 20 patients. In the first block of interventions, oxygenation and respiratory mechanics parameters did not differ between $\mathrm{VPSV}_{15 \%}$ and $\mathrm{VPSV}_{30 \%}$ 
compared with $P S V_{0 \%}$. The variability of tidal volume $\left(V_{T}\right)$ was higher with $\mathrm{PPSV}_{15 \%}$ and $\mathrm{VPSV}_{30 \%}$ compared with $\mathrm{PSV}_{0 \%}$. The incidence of asynchronies and the variability of transpulmonary pressure $\left(P_{\mathrm{L}}\right)$ were higher with $\mathrm{VPSV}_{30 \%}$ compared with $\mathrm{PSV}_{0 \%}$. In the second block of interventions, different levels of pressure support with and without variability did not change oxygenation. The variability of $V_{T}$ and $P_{L}$ was higher with $\mathrm{vPSV}_{-5}$ compared with $\mathrm{PSV}_{-5}$, but not with $\mathrm{VPSV}_{\mathrm{BL}}$ compared with $\mathrm{PSV}_{\mathrm{BL}}$.

Conclusion: In patients with mild-moderate ARDS, the addition of variability did not improve oxygenation at different pressure support levels. Moreover, high variability levels were associated with worse patient-ventilator synchrony.

Clinical Trial Registration: www.clinicaltrials.gov, identifier: NCT01683669.

Keywords: variable pressure support ventilation, acute respiratory distress (ARDS), asynchronies, respiratory mechanic, assisted ventilation

\section{INTRODUCTION}

Pressure support ventilation (PSV) is an assisted ventilation mode commonly used in critically ill patients (Esteban et al., 2013). The maintenance of spontaneous respiratory activity in acute respiratory distress syndrome (ARDS) patients improves respiratory function and decreases the need for vasopressor and sedative drugs (Putensen et al., 2001). Assisted ventilation modes have been commonly used in the management of patients with ARDS, in particular those with mild to moderate hypoxemic respiratory failure (Bellani et al., 2016).

In the last years, researchers have proposed to vary the level of pressure support on a breath-by-breath basis to restore the physiological variability of breathing activity (Tobin et al., 1988). Variable pressure support ventilation (vPSV), compared with conventional PSV, improved oxygenation in the experimental models of ARDS (Gama de Abreu et al., 2008) and ventilatorpatient synchrony in a small pilot study in critically ill patients with acute respiratory failure (Spieth et al., 2013). These effects could be mediated by an amelioration of the ventilationperfusion matching (Huhle et al., 2016), as well as a recruitment effect due to the repetitive delivery of breaths with a higher tidal volume, which might also result in a reduction of lung inhomogeneity (Mauri et al., 2017). However, so far, the only clinical study published has used only one variability level at fixed pressure support $\left(\Delta P_{\mathrm{S}}\right)$ (Spieth et al., 2013). Therefore,

\footnotetext{
Abbreviations: PSV, pressure support ventilation; ARDS, acute respiratory distress syndrome; vPSV, variable pressure support ventilation; $\Delta P_{\mathrm{S}}$, pressure support level; ICU, intensive care unit; PEEP, positive end-expiratory pressure; PBW, predicted body weight; SAPS, simplified acute physiology score; SOFA, sequential organ failure assessment score; RASS, richmond agitation-sedation scale; $\mathrm{PSV}_{0 \%}$, pressure support ventilation with no variability; $\mathrm{vPSV}_{15 \%}$, variable pressure support ventilation with $15 \% \mathrm{CV}$ variability; $\mathrm{vPSV}_{30 \%}$, variable pressure support ventilation with $30 \% \mathrm{CV}$ variability; $V_{\mathrm{T}}$, tidal volume; PTP, esophageal pressuretime product; $\Delta P_{\mathrm{es}}$, esophageal pressure swings; $P_{\mathrm{L}}$, peak transpulmonary pressure; $P S V_{B L}$, pressure support ventilation with no variability and baseline $\Delta P_{\mathrm{S}}$ as per clinical indication; $\mathrm{vPSV}_{\mathrm{BL}}$, variable pressure support with variability set to achieve $\pm 5 \mathrm{cmH}_{2} \mathrm{O}$ and baseline $\Delta P_{\mathrm{S}}$ as per clinical indication; $\mathrm{PSV}_{-5}$, pressure support ventilation with no variability and $\Delta P_{\mathrm{S}}$ reduced by $5 \mathrm{cmH}_{2} \mathrm{O}$ from the baseline value; $\mathrm{vPSV}_{-5}$, variable pressure support ventilation with variability set to achieve $\pm 5 \mathrm{cmH}_{2} \mathrm{O}$ and $\Delta P_{\mathrm{S}}$ reduced by $5 \mathrm{cmH}_{2} \mathrm{O}$ from the baseline value.
}

the effects of different levels of variability and the impact of variability at different $\Delta P_{\mathrm{S}}$ levels remain unknown. Different levels of variability might modify differently the ventilation perfusion-matching and might affect differently gas exchange and respiratory mechanics.

The aim of this study was to evaluate the effects of vPSV, at different levels of variability and pressure support, on shortterm lung function parameters in patients with mild to moderate ARDS. We tested the hypothesis that vPSV would improve gas exchange, respiratory mechanics, and patient-ventilator asynchrony. We also hypothesized that the degree of variability and the level of $\Delta P_{S}$ would influence the effects of vPSV.

\section{METHODS \\ Study Design}

This was a prospective, crossover, randomized clinical trial conducted in a single university hospital intensive care unit (ICU).

\section{Inclusion and Exclusion Criteria}

Patients aged $>18$ years with mild to moderate ARDS $\left(\mathrm{PaO}_{2} / \mathrm{FIO}_{2}\right.$ ratio between 100 and $300 \mathrm{mmHg}$ with a positive end-expiratory pressure, PEEP $\geq 5 \mathrm{cmH}_{2} \mathrm{O}$ ) already receiving PSV per clinical indication were screened for inclusion. Exclusion criteria were pregnancy, chronic obstructive pulmonary disease, presence of pneumothorax or chest tubes, and unavailability of research staff.

\section{Interventions}

According to the local clinical practice, conventional PSV was delivered by an Evita Infinity V500 ventilator (Dräger Medical AG, Lübeck, Germany) targeting a $V_{\mathrm{T}}$ of $6-8 \mathrm{ml} / \mathrm{kg}$ of predicted body weight, respiratory rate $\leq 25 \mathrm{~min}^{-1}$ with $\mathrm{PEEP}$ and $\mathrm{FIO}_{2}$ titrated to achieve a peripheral oxygen saturation $\geq 92 \%$. This ventilator can operate in vPSV mode setting the variability of the $\Delta P_{\mathrm{S}}$ and delivers breaths with an approximately Gaussian distribution, truncated at $3 \mathrm{SDs}$ from the mean $\Delta P_{\mathrm{S}}$. The parameter "variability" of this ventilator refers to the range of $\Delta P_{S}$, e.g., $90 \%$ "variability" results in a $30 \%$ coefficient 


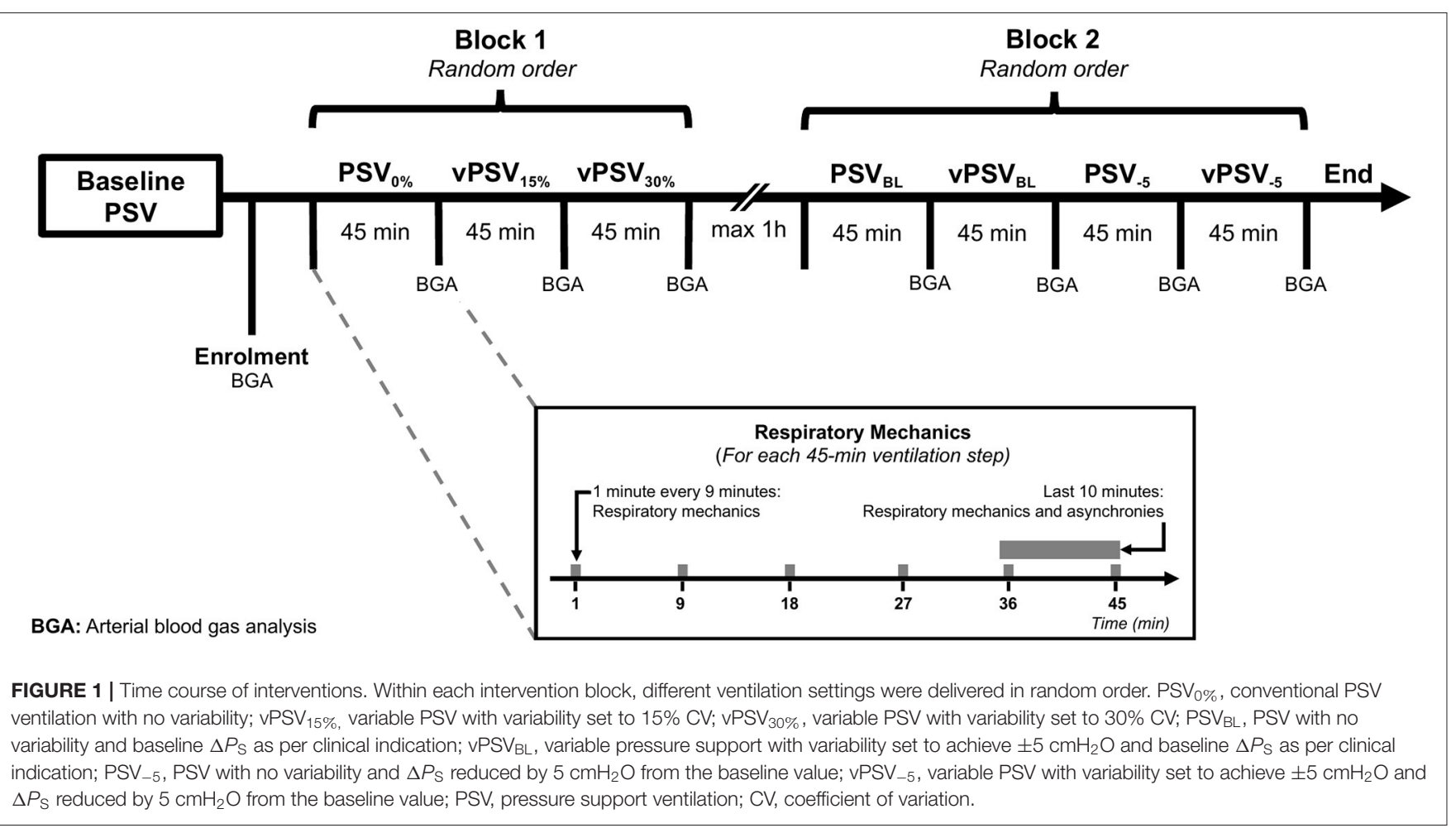

of variation $(\mathrm{CV})$. As illustrated in Figure 1, all patients underwent two blocks of interventions, receiving 45-min periods of ventilation with different settings. In the first block, the effects of three levels of variability were tested at constant $\Delta P_{S}$ to explore the effect of variability added to a fixed $\Delta P_{\mathrm{S}}$ level, while in the second block, a variability of $\pm 5 \mathrm{cmH}_{2} \mathrm{O}$ was added to $\Delta P_{\mathrm{S}}$ set at either the baseline level or the baseline level minus $5 \mathrm{cmH}_{2} \mathrm{O}$, to investigate the effects of variability at two $\Delta P_{\mathrm{S}}$ levels. During the first block, the $\Delta P_{\mathrm{S}}$ was set at a fixed value corresponding to the level chosen by the treating clinician before enrolment, and three different CV\% levels were used: $0 \%\left(\mathrm{PSV}_{0 \%}\right), 15 \%$ $\left(\mathrm{vPSV}_{15 \%}\right)$, and $30 \%\left(\mathrm{vPSV}_{30 \%}\right)$. During the second block, four ventilation settings were used: PSV with baseline $\Delta P_{\mathrm{S}}\left(\mathrm{PSV}_{\mathrm{BL}}\right)$, baseline $\Delta P_{\mathrm{S}}$ with variability set individually to $\pm 5 \mathrm{cmH}_{2} \mathrm{O}$ (vPSV $\mathrm{BL}_{\mathrm{BL}}$ ), $\Delta P_{\mathrm{S}}$ reduced by $5 \mathrm{cmH}_{2} \mathrm{O}$ compared with the baseline with either no variability $\left(\mathrm{PSV}_{-5}\right)$ or variability set to \pm 5 $\mathrm{cmH}_{2} \mathrm{O}$ (vPSV -5 ). The two blocks were performed sequentially, within $1 \mathrm{~h}$ from each other to allow for nursing assistance if required, and ventilation modes within each intervention block were assigned in random order with a Latin square design (as shown in Figure 1; Supplementary Figures 1, 2). The randomization sequence was generated with an online service, and a sealed envelope was opened at the moment of patient enrolment. Participants were blinded to the treatment assignment as were the operators involved in respiratory mechanics analysis.

Patient management procedures not related to mechanical ventilation, including sedation and fluid administration, were at the discretion of the treating clinician. When clinically feasible, we avoided changing $\mathrm{FIO}_{2}, \mathrm{PEEP}$, and $\Delta P_{\mathrm{S}}$ during the study, and in case of desaturation below 92\%, $\mathrm{FIO}_{2}$ increase was prioritized over PEEP increase. After completion of the study protocol, ventilation was continued at the discretion of the treating physician.

\section{Measurements}

An esophageal balloon catheter (Compliance catheter, Microtek Medical B.V., Zutphen, The Netherlands) was inserted through the nose or mouth, filled with $1.5 \mathrm{ml}$, and correct positioning was verified with an occlusion maneuver (Akoumianaki et al., 2014). The flow was measured with a heated Fleisch-type pneumotachograph connected to a multi-channel transducer (ICU Lab, KleisTEK Engineering, Bari, Italy), while the tidal volume was measured as the integral of flow over time. Respiratory traces were recorded continuously throughout the study. An arterial blood gas analysis, heart rate, and invasive mean arterial pressure were recorded at baseline and the end of each ventilation step.

Pressure-time and flow-time curves were analyzed offline with a dedicated script written in MATLAB (MathWorks, MA, USA). The following parameters were computed breath by breath: $\mathrm{V}_{\mathrm{T}}$, PEEP, $\Delta P_{S}$, mean airway pressure, inspiratory time to total time ratio $\left(T_{\text {insp }} / T_{\text {tot }}\right)$, respiratory rate $(\mathrm{RR})$, esophageal pressure swings $\left(\Delta P_{\mathrm{es}}\right)$, and peak transpulmonary pressure $\left(\mathrm{P}_{\mathrm{L}}\right)$. The respiratory muscle activity was quantified with the esophageal pressure-time product per $\min \left(\mathrm{PTP}_{\mathrm{es}}\right)$, calculated as follows (Mauri et al., 2016):

$$
P T P_{e s, \text { min }}=R R \cdot \int P_{m u s} d t=R R \cdot \int\left(P_{c w, \text { recoil }}-P_{e s}\right) d t
$$


where $P_{\text {mus }}$ is the pressure generated by the respiratory muscles, and $P_{\mathrm{cw} \text {,recoil }}$ is the chest wall recoil pressure, calculated assuming a fixed elastance of $5 \mathrm{cmH}_{2} \mathrm{O} / \mathrm{L}$. The asynchrony index was computed as the number of asynchronous events divided by the total number of ventilator cycles plus ineffective efforts during expiration multiplied by 100 (Blanch et al., 2015). Asynchronies were classified independently by two experienced operators (LB and MV), and discrepancies were resolved by consensus. The analysis of respiratory mechanics data was performed by three operators blinded to the ventilation settings (ADO, MF, and LM). Also, we measured the evolution of respiratory mechanics at min $1,9,18,27,36$, and 45 from the start of each ventilation step. To allow sufficient time for patient adaptation, main analyses of respiratory mechanics and asynchronies were restricted to the last $10 \mathrm{~min}$ of each ventilation step.

\section{Data Analysis and Sample Size Calculation}

All variables are reported as medians [25th -75 th percentile], if not otherwise specified. Measurements on multiple breaths were aggregated within-patients computing the median and the $\mathrm{CV}$; then, between-patients medians [ $25 \mathrm{th}-75$ th percentile] were computed. Comparisons between continuous variables during the different ventilation steps were sought with Friedman's test and Dunn's post-hoc test. The primary endpoint was the partial pressure of arterial oxygen to $\mathrm{FiO}_{2}$ ratio $\left(\mathrm{PaO}_{2} / \mathrm{FiO}_{2}\right)$. From internal administrative data, we expected a baseline $\mathrm{PaO}_{2} / \mathrm{FiO}_{2}$ around $150 \pm 50 \mathrm{mmHg}$. Using a Latin square crossover design, and assuming an intra-subject correlation of the $\mathrm{PaO}_{2} / \mathrm{FiO}_{2}$ between treatments with $\rho=0.75$, we needed to enroll at least 16 patients to achieve $90 \%$ power ( 1 $\beta$ ) to detect a $20 \%$ relative increase in the $\mathrm{PaO}_{2} / \mathrm{FiO}_{2}$ ratio (Muller and Barton, 1989; Muller et al., 1992). To account for potential drop-off or missing respiratory mechanics data, we aimed to enroll 20 patients. Repeated measurement analysis of respiratory mechanics parameters at different timepoints within each ventilation block was performed using mixed-effects linear models using patients as random effects and timepoint, ventilation, and their interaction as fixed effects.

In one post-hoc analysis, associations were determined between the respiratory mechanics parameters of each breath and the $\Delta P_{\mathrm{S}}$ received during the preceding breath in the ${ }_{\mathrm{vPSV}} \mathrm{BL}$ and $\mathrm{vPSV}_{-5}$ ventilation steps. For this purpose, mixed-effects linear models were used, using patients as random effects and the $\Delta P_{\mathrm{S}}$ received during the preceding breath as the fixed effect.

All analyses were performed with R 3.2.3 (The R Foundation for Statistical Computing, www.r-project.org). Statistical significance was considered for two-tailed $p<0.05$.

\section{RESULTS}

Twenty patients were enrolled and completed the study. Baseline characteristics are presented in Table 1. The $\mathrm{FiO}_{2}$ and PEEP were kept constant during the study in all patients; one patient required $\Delta P_{\mathrm{S}}$ reduction between ventilation block 1 and block 2 according to the treating clinician decision for reasons unrelated to the study procedures. Tables 2,3 show respiratory mechanics, hemodynamics, and arterial blood gas analysis
TABLE 1 | Baseline characteristics of patients.

\begin{tabular}{|c|c|}
\hline \multicolumn{2}{|l|}{ Patient characteristics } \\
\hline Number of patients & 20 \\
\hline Age (years) & 72 [59-79] \\
\hline Female sex (N, \%) & $6 / 20(30 \%)$ \\
\hline Weight (kg) & $80[64-87]$ \\
\hline Height $(\mathrm{cm})$ & $175[165-180]$ \\
\hline Body mass index $\left(\mathrm{kg} / \mathrm{m}^{2}\right)$ & $25.8[22.7-29.5]$ \\
\hline PBW (kg) & $71[58-75]$ \\
\hline SAPS ॥ & $53[38-60]$ \\
\hline SOFA & $7[6-9]$ \\
\hline RASS & $-3[-3$ to -1$]$ \\
\hline Sedative drugs (N, \%) & $\begin{array}{l}\text { Propofol 5/20 (25\%) } \\
\text { Dexmedetomidine 3/20 (15\%) } \\
\text { Midazolam 4/20 (20\%) } \\
\text { None 8/20 (40\%) }\end{array}$ \\
\hline Analgesic drugs (N, \%) & $\begin{array}{l}\text { Fentanyl 8/20 (40\%) } \\
\text { Morphine 2/20 (10\%) } \\
\text { None 10/20 (50\%) }\end{array}$ \\
\hline Days of ventilation prior to inclusion & $7[5-9]$ \\
\hline Primary reason for admission to the ICU & $\begin{array}{l}\text { Acute respiratory failure: } \\
10(50 \%) \\
\text { Multiple trauma: } 4(20 \%) \\
\text { Brain hemorrhage: } 3(15 \%) \\
\text { Post-cardiac arrest: } 3(15 \%)\end{array}$ \\
\hline Risk factor for development of ARDS & $\begin{array}{l}\text { Pneumonia: } 11 \text { (55\%) } \\
\text { Multiple fractures: } 2 \text { (10\%) } \\
\text { Sepsis: } 4 \text { (20\%) } \\
\text { Aspiration pneumonia: } 3(15 \%)\end{array}$ \\
\hline $\begin{array}{l}\text { Blood gas analysis at enrolment } \\
\mathrm{PaO}_{2}(\mathrm{mmHg})\end{array}$ & $97[79-120]$ \\
\hline $\mathrm{PaCO}_{2}(\mathrm{mmHg})$ & $40[36-46]$ \\
\hline $\mathrm{pHa}$ & $7.46[7.44-7.51]$ \\
\hline $\mathrm{PaO}_{2} / \mathrm{FIO}_{2}$ ratio $(\mathrm{mmHg})$ & 198 [154-250] \\
\hline \multicolumn{2}{|l|}{ Ventilator settings at enrolment } \\
\hline$\Delta P_{\mathrm{S}}\left(\mathrm{cmH}_{2} \mathrm{O}\right)$ & $15[14-17]$ \\
\hline $\operatorname{PEEP}\left(\mathrm{cmH}_{2} \mathrm{O}\right)$ & $6[5-8]$ \\
\hline $\mathrm{FIO}_{2}(\%)$ & $50[43-58]$ \\
\hline Tidal volume (mL/kg of PBW) & $7.5[7.0-8.5]$ \\
\hline Respiratory rate $\left(\mathrm{min}^{-1}\right)$ & $15[13-20]$ \\
\hline
\end{tabular}

PBW, predicted body weight; PEEP, positive end-expiratory pressure; $\triangle P_{S}$, pressure support; SAPS, simplified acute physiology score; SOFA, sequential organ failure assessment score; RASS, richmond agitation-sedation scale; ICU, intensive care unit.

in ventilation blocks 1 and 2, respectively. The distribution of key respiratory mechanics parameters in ventilation blocks 1 and 2 is illustrated in Figures 2, 3, respectively. Supplementary Figures 3-11 report details the evolution over time of the respiratory mechanics parameters in the different ventilation steps.

\section{Block 1: Physiological Effects of Different Variability Levels at Constant $\Delta \mathrm{P}_{\mathbf{S}}$}

The $\mathrm{PaO}_{2} / \mathrm{FiO}_{2}$ did not differ between ventilation steps in block $1(p=0.62$, Table 2). Median respiratory mechanics variables, other gas exchange, and hemodynamic parameters did not 
TABLE 2 | Gas exchange, hemodynamics, and respiratory mechanics in patients during pressure support ventilation at different levels of variability (Block 1).

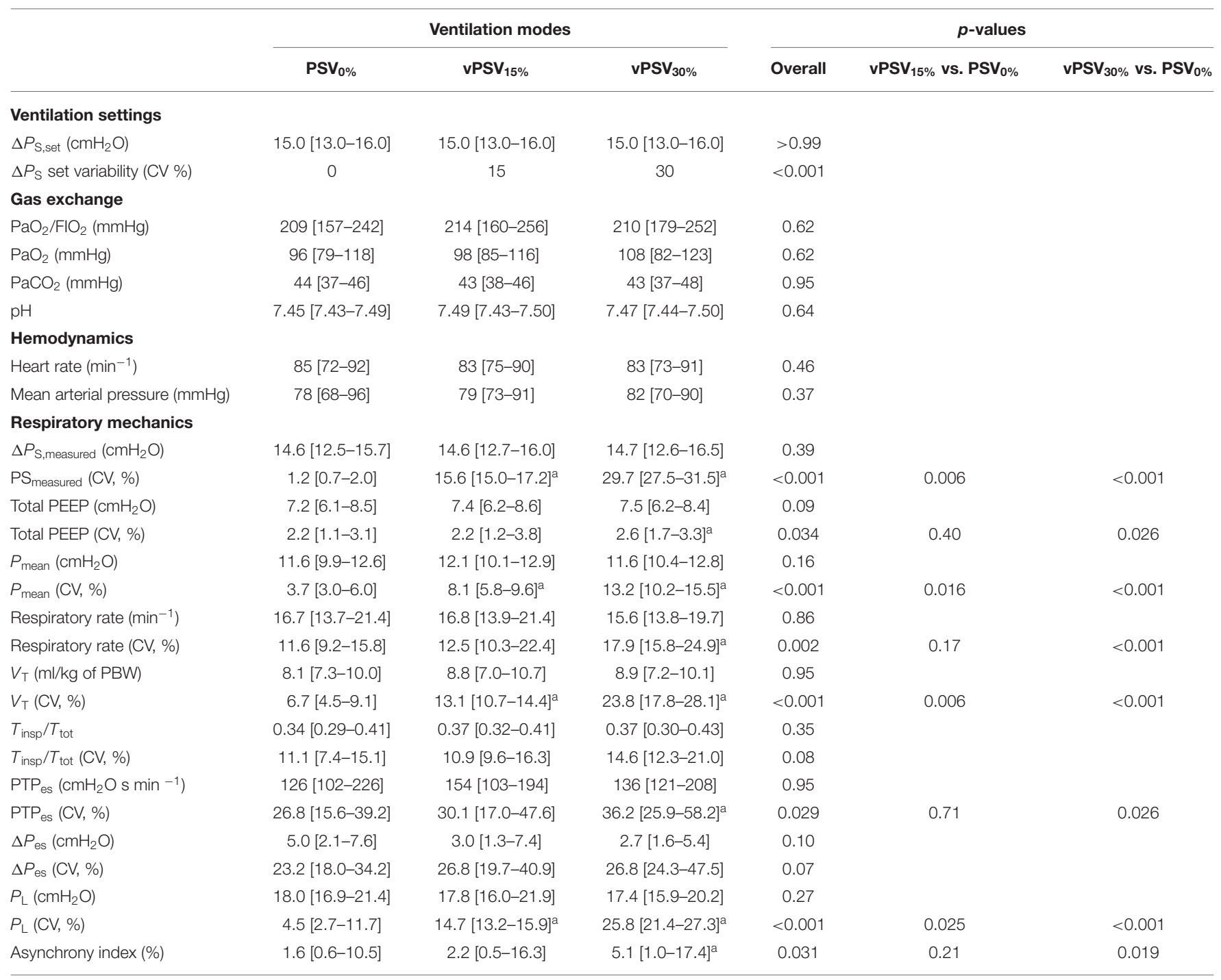

Values are computed during the last $10 \mathrm{~min}$ of a 45-min ventilation period. Data are reported as inter-subject median [25th-75th percentile] of the intra-subject median values. ${ }^{a}$ Significantly different from PSV $0 \%$. PSV $0 \%$, pressure support ventilation with no variability; $v P S V_{15 \%}$, variable pressure support ventilation with $15 \% \mathrm{CV}$ variability; $v P S V_{30 \%}$, variable pressure support ventilation with $30 \% \mathrm{CV}$ variability.

$C V$, coefficient of variation; PEEP, positive end-expiratory pressure; PBW, predicted body weight; $\Delta P_{S}$, pressure support; $V_{T}$, tidal volume; PTP, esophageal pressure-time product; $\Delta P_{e s}$, esophageal pressure swings; $P_{L}$, peak transpulmonary pressure.

change between $\mathrm{vPSV}_{15 \%}$ and $\mathrm{vPSV}_{30 \%}$ compared with $\mathrm{PSV}_{0 \%}$ (Table 2). However, the variability of $\triangle P_{S}, \mathrm{PEEP}_{\text {tot }}, P_{\text {mean }}$, and $V_{\mathrm{T}}$ was higher with $\mathrm{PSV}_{15 \%}$ and $\mathrm{PSV}_{30 \%}$ compared with $\mathrm{PSV}_{0 \%}$ (Table 2). The RR and $\mathrm{PTP}_{\mathrm{es} \text {,min }}$ had higher variability only with $\mathrm{vPSV}_{30 \%}$ (Table 2). Moreover, asynchronies were more frequent with vPSV $30 \%$ compared with $\operatorname{PSV}_{0 \%}(p=0.019$, Table 2$)$.

\section{Block 2: Physiological Effects of Variability at Two Levels of $\Delta P_{S}$}

The $\mathrm{PaO}_{2} / \mathrm{FiO}_{2}$, as well as other gas exchange and hemodynamic parameters, did not differ between ventilation steps in block 2 (Table 3). Ventilation modes with $\Delta P_{\mathrm{S}}$ reduced by $5 \mathrm{cmH}_{2} \mathrm{O}$ $\left(\mathrm{PSV}_{-5}\right.$ and $\mathrm{vPSV}_{-5}$ ) had lower $P_{\text {mean }}, V_{\mathrm{T}}, P_{\mathrm{L}}$, and higher $\mathrm{RR}$ (Table 3). Adding $\pm 5 \mathrm{cmH}_{2} \mathrm{O}$ variability (vPSV $\mathrm{BL}_{\mathrm{BL}}$ and
$\mathrm{vPSV}_{-5}$ steps) increased the variability of $\Delta P_{\mathrm{S}}$ and $P_{\text {mean }}$ compared to PSV without variability at the corresponding $\Delta P_{\mathrm{S}}$ level. Adding $\pm 5 \mathrm{cmH}_{2} \mathrm{O}$ variability increased the variability of $V_{\mathrm{T}}$ and $P_{\mathrm{L}}$ only when using the baseline $\Delta P_{\mathrm{S}}$, but not when the $\Delta P_{\mathrm{S}}$ was reduced by $5 \mathrm{cmH}_{2} \mathrm{O}$. The incidence of asynchronies was not different between ventilation steps in block 2 (Table 3 ).

Tables 2, 3 report extensive details on respiratory mechanics, hemodynamics, and arterial blood gas analysis in ventilation blocks 1 and 2, respectively. The distribution of key respiratory mechanics parameters in ventilation blocks 1 and 2 is illustrated in Figures 3, 4, respectively. Supplemental Figures 3-11 report details the evolution over time of the respiratory mechanics parameters in the different ventilation steps. 
TABLE 3 | Gas exchange, hemodynamics, and respiratory mechanics in patients during pressure support ventilation at different variability and pressure support level (Block 2).

p-values

\begin{tabular}{|c|c|c|c|c|c|c|c|c|}
\hline & & & & & \\
\hline & $\mathrm{PSV}_{\mathrm{BL}}$ & vPSV $_{B L}$ & $\mathrm{PSV}_{-5}$ & vPSV $_{-5}$ & Overall & vPSV $_{B L}$ vs. $P V_{B L}$ & $\mathrm{PSV}_{-5}$ vs. $\mathrm{PSV}_{\mathrm{BL}}$ & vPSV $_{-5}$ vs. $\mathrm{PSV}_{-5}$ \\
\hline \multicolumn{9}{|l|}{ Ventilator Settings } \\
\hline$\Delta P_{S}$ setting & \multicolumn{2}{|c|}{ Baseline } & \multicolumn{2}{|c|}{ Baseline $-5 \mathrm{cmH}_{2} \mathrm{O}$} & & & & \\
\hline$\Delta P_{\mathrm{S}, \text { set }}\left(\mathrm{cmH}_{2} \mathrm{O}\right)$ & 14.0 [12.0-16.0] & $14.0[12.0-16.0]$ & $9.0[7.0-11.0]$ & $9.0[7.0-11.0]$ & $<0.001$ & 0.99 & $<0.001$ & $<0.001$ \\
\hline Variability setting & None & $\pm 5 \mathrm{cmH}_{2} \mathrm{O}$ & No variability & $\pm 5 \mathrm{cmH}_{2} \mathrm{O}$ & & & & \\
\hline$\Delta P_{\mathrm{S}}$ set variability (CV \%) & $0[0-0]$ & $11[9-13]$ & $0[0-0]$ & 15 [13-20] & $<0.001$ & $<0.001$ & 0.99 & $<0.001$ \\
\hline \multicolumn{9}{|l|}{ Gas exchange } \\
\hline $\mathrm{PaO}_{2} / \mathrm{FIO}_{2}(\mathrm{mmHg})$ & 213 [180-229] & 194 [180-229] & 215 [183-239] & $197[167-224]$ & 0.61 & & & \\
\hline $\mathrm{PaO}_{2}(\mathrm{mmHg})$ & 95 [89-117] & 99 [87-115] & 99 [90-121] & 98.8 [85-1112] & 0.61 & & & \\
\hline $\mathrm{PaCO}_{2}(\mathrm{mmHg})$ & $42[39-46]$ & $43[39-48]$ & $44[40-49]$ & $44[40-51]$ & 0.18 & & & \\
\hline $\mathrm{pH}$ & $7.47[7.43-7.49]$ & $7.48[7.43-7.49]$ & $7.47[7.43-7.48]$ & $7.47[7.42-7.48]$ & 0.21 & & & \\
\hline \multicolumn{9}{|l|}{ Hemodynamics } \\
\hline Heart rate $\left(\mathrm{min}^{-1}\right)$ & 83 [77-93] & 84 [77-92] & 84 [77-92] & 86 [76-92] & 0.46 & & & \\
\hline Mean arterial pressure $(\mathrm{mmHg})$ & 88 [81-93] & 82 [78-87] & 80 [77-90] & 86 [77-90] & 0.37 & & & \\
\hline \multicolumn{9}{|l|}{ Respiratory mechanics } \\
\hline$\Delta P_{\mathrm{S}, \text { measured }}\left(\mathrm{cmH}_{2} \mathrm{O}\right)$ & $13.2[12.0-15.8]$ & $13.6[12.5-15.9]$ & $8.4[7.0-10.5]^{\mathrm{a}}$ & $8.5[7.2-10.7]$ & $<0.001$ & 0.92 & $<0.001$ & 0.67 \\
\hline$\Delta P_{\text {Smeasured }}(\mathrm{CV}, \%)$ & $1.5[0.9-4.8]$ & $12.1[11.1-14.3]^{\mathrm{a}}$ & $2.3[1.7-6.6]$ & $17.9[15.2-18.6]^{\mathrm{b}}$ & $<0.001$ & 0.001 & 0.99 & $<0.001$ \\
\hline Total PEEP $\left(\mathrm{cmH}_{2} \mathrm{O}\right)$ & $7.6[6.2-8.4]$ & $7.5[6.2-8.5]$ & $7.7[5.8-8.7]^{a}$ & $7.7[5.7-8.7]$ & 0.001 & 0.99 & 0.009 & 0.92 \\
\hline Total PEEP (CV, \%) & $2.3[1.4-4.9]$ & $2.6[1.8-8.0]$ & $2.1[1.6-4.3]$ & $2.4[1.4-5.9]$ & 0.09 & & & \\
\hline$P_{\text {mean }}\left(\mathrm{cmH}_{2} \mathrm{O}\right)$ & $11.0[9.7-12.6]$ & $11.2[9.7-13.1]$ & $9.7[8.4-11.9]^{a}$ & $9.8[8.4-11.8]$ & $<0.001$ & 0.67 & $<0.001$ & 0.99 \\
\hline$P_{\text {mean }}(\mathrm{CV}, \%)$ & $5.4[3.4-8.2]$ & $8.1[5.5-10.2]^{\mathrm{a}}$ & $2.5[1.8-5.0]$ & $6.0[4.5-7.3]^{\mathrm{b}}$ & $<0.001$ & 0.014 & 0.11 & 0.029 \\
\hline Respiratory rate $\left(\min ^{-1}\right)$ & $14.7[13.7-18.3]$ & $17.6[14.8-19.4]$ & $22.9[16.0-24.9]^{\mathrm{a}}$ & $20.1[16.9-26.8]$ & 0.022 & 0.96 & 0.041 & 0.95 \\
\hline Respiratory rate (CV, \%) & $18.8[10.6-46.4]$ & $32.0[16.1-60.3]$ & $13.1[6.2-35.2]$ & $14.6[9.7-17.7]$ & 0.003 & 0.43 & 0.43 & 0.99 \\
\hline$V_{T}(\mathrm{ml} / \mathrm{kg}$ of $\mathrm{PBW})$ & $8.5[7.2-9.4]$ & 8.2 [7.0-9.1] & $7.0[5.9-7.6]^{\mathrm{a}}$ & $7.2[6.0-7.7]$ & $<0.001$ & 0.92 & $<0.001$ & 0.67 \\
\hline$V_{\mathrm{T}}(\mathrm{CV}, \%)$ & $9.3[5.1-15.7]$ & $12.7[11.1-15.3]^{\mathrm{a}}$ & $8.3[4.2-13.6]$ & $10.8[9.4-14.6]$ & 0.003 & 0.006 & 0.99 & 0.74 \\
\hline$T_{\text {insp }} / T_{\text {tot }}$ & $0.36[0.30-0.37]$ & 0.37 [0.30-0.39] & $0.36[0.32-0.39]$ & $0.35[0.32-0.38]$ & 0.42 & & & \\
\hline$T_{\text {insp }} / T_{\text {tot }}(\mathrm{CV}, \%)$ & $9.3[5.1-15.7]$ & $12.7[11.1-15.3]^{\mathrm{a}}$ & $8.3[4.2-13.6]$ & $10.8[9.4-14.6]$ & 0.058 & & & \\
\hline $\mathrm{PTP}_{\mathrm{es}}\left(\mathrm{cmH}_{2} \mathrm{O} \mathrm{s} \mathrm{min}{ }^{-1}\right)$ & $155.2[118.4-262.8]$ & $161.4[87.1-248.3]$ & 215.0 [128.1-357.9] & $259.1[151.1-422.8]$ & 0.001 & 0.51 & 0.18 & 0.99 \\
\hline $\mathrm{PTP}_{\mathrm{es}}(\mathrm{CV}, \%)$ & 31.8 [20.6-52.3] & $53.8[23.9-71.1]$ & $27.5[16.0-40.5]$ & $30.7[18.5-44.7]$ & 0.005 & 0.08 & 0.75 & 0.81 \\
\hline$\Delta P_{\mathrm{es}}\left(\mathrm{cmH}_{2} \mathrm{O}\right)$ & 4.4 [2.1-9.3] & $5.3[1.3-8.0]$ & $5.6[1.6-11.8]$ & $10.4[2.6-14.1]$ & $<0.001$ & 0.59 & 0.59 & 0.43 \\
\hline$\Delta P_{\text {es }}(\mathrm{CV}, \%)$ & 32.7 [21.1-45.5] & 40.9 [22.3-53.5] & $22.8[13.1-31.5]$ & 20.6 [12.7-32.2] & $<0.001$ & 0.51 & 0.29 & 0.67 \\
\hline$P_{\mathrm{L}}\left(\mathrm{cmH}_{2} \mathrm{O}\right)$ & $18.5[15.9-23.2]$ & $18.6[16.1-23.4]$ & $14.6[11.5-20.8]^{\mathrm{a}}$ & $18.0[14.0-21.6]$ & $<0.001$ & 0.99 & $<0.001$ & 0.67 \\
\hline$P_{\mathrm{L}}(\mathrm{CV}, \%)$ & 7.5 [3.8-12.6] & $12.2[11.1-17.0]^{\mathrm{a}}$ & $10.0[4.2-13.1]$ & $15.7[12.4-17.3]$ & 0.009 & 0.042 & 0.95 & 0.14 \\
\hline Asynchrony index (\%) & $1.5[0.7-7.2]$ & $2.4[0.1-12.6]$ & 0.9 [0.0-7.6] & $1.3[0-3.9]$ & 0.21 & & & \\
\hline
\end{tabular}

Values are computed during the last $10 \mathrm{~min}$ of a 45 -min ventilation period. Data are reported as inter-subject median [25th-75th percentile] of the intra-subject median values

${ }^{a}$ Significant difference compared to PSV $B L(p<0.05)$.

${ }^{b}$ Significant difference compared to $P S V_{-5}(p<0.05)$.

$P S V_{B L}$, pressure support ventilation with no variability and baseline $\triangle P_{S}$ as per clinical indication; $v P S V_{B L}$, variable pressure support with variability set to achieve $\pm 5 \mathrm{~cm} H_{2} O$ and baseline $\triangle P_{S}$ as per clinical indication; $P S V_{-5}$, pressure support ventilation with no variability and $\Delta P_{S}$ reduced by $5 \mathrm{cmH}_{2} \mathrm{O}$ from the baseline value; $v P S V_{-5}$, variable pressure support ventilation with variability set to achieve $\pm 5 \mathrm{cmH}_{2} \mathrm{O}$ and $\Delta P_{S}$ reduced by $5 \mathrm{cmH}_{2} \mathrm{O}$ from the baseline value; $C V$, coefficient of variation; $P E E P$, positive end-expiratory pressure; $P B W$, predicted body weight; $\triangle P_{S}$, pressure support; $V_{T}$, tidal volume; PTP, esophageal pressure-time product; $\triangle P_{\text {es }}$, esophageal pressure swings; $P_{L}$, peak transpulmonary pressure. 

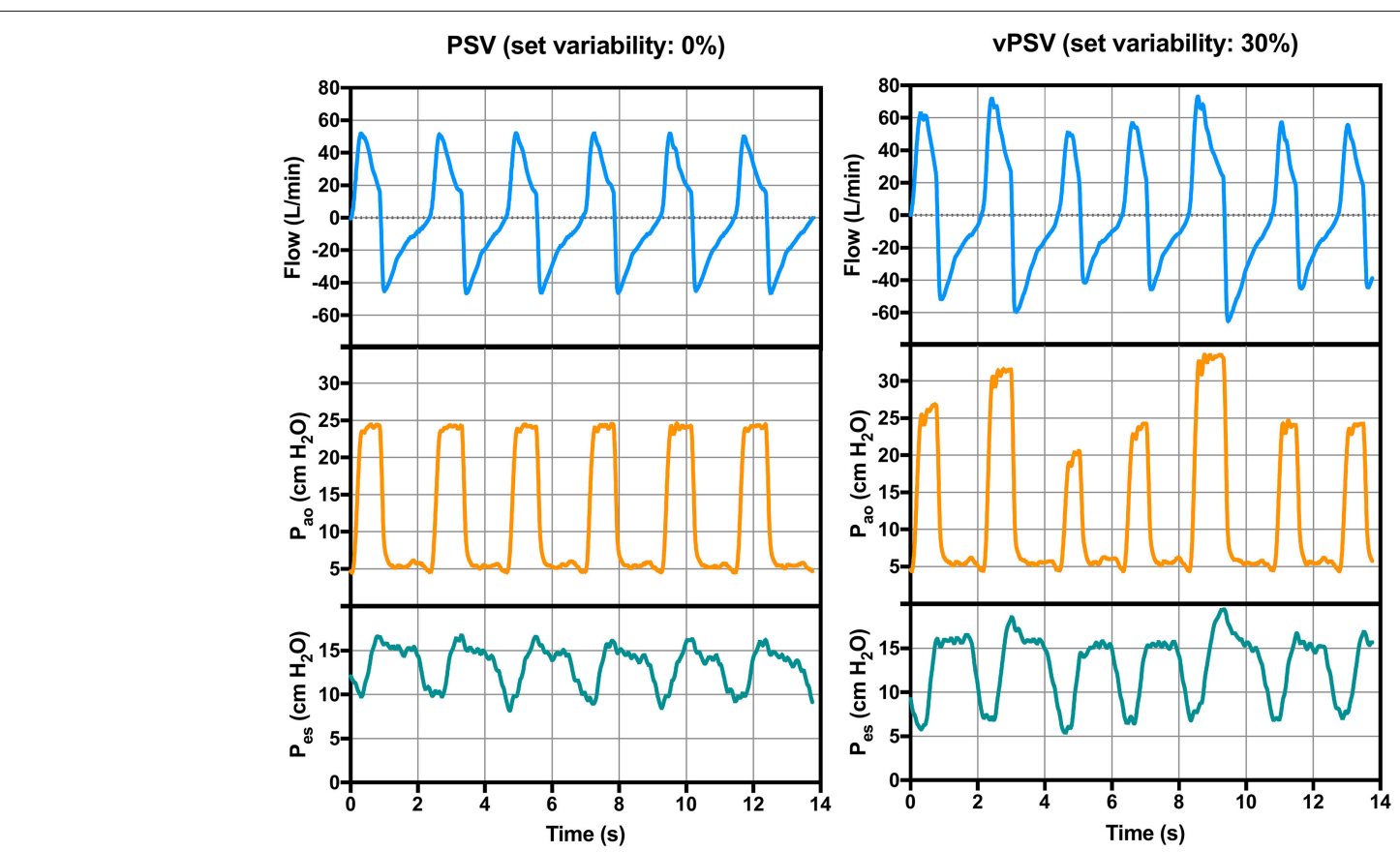

FIGURE 2 | Representative respiratory traces of a patient during conventional (left) and variable (right) pressure support ventilation. $P_{\text {ao, }}$ pressure at the airway opening; $P_{\text {es }}$, esophageal pressure.
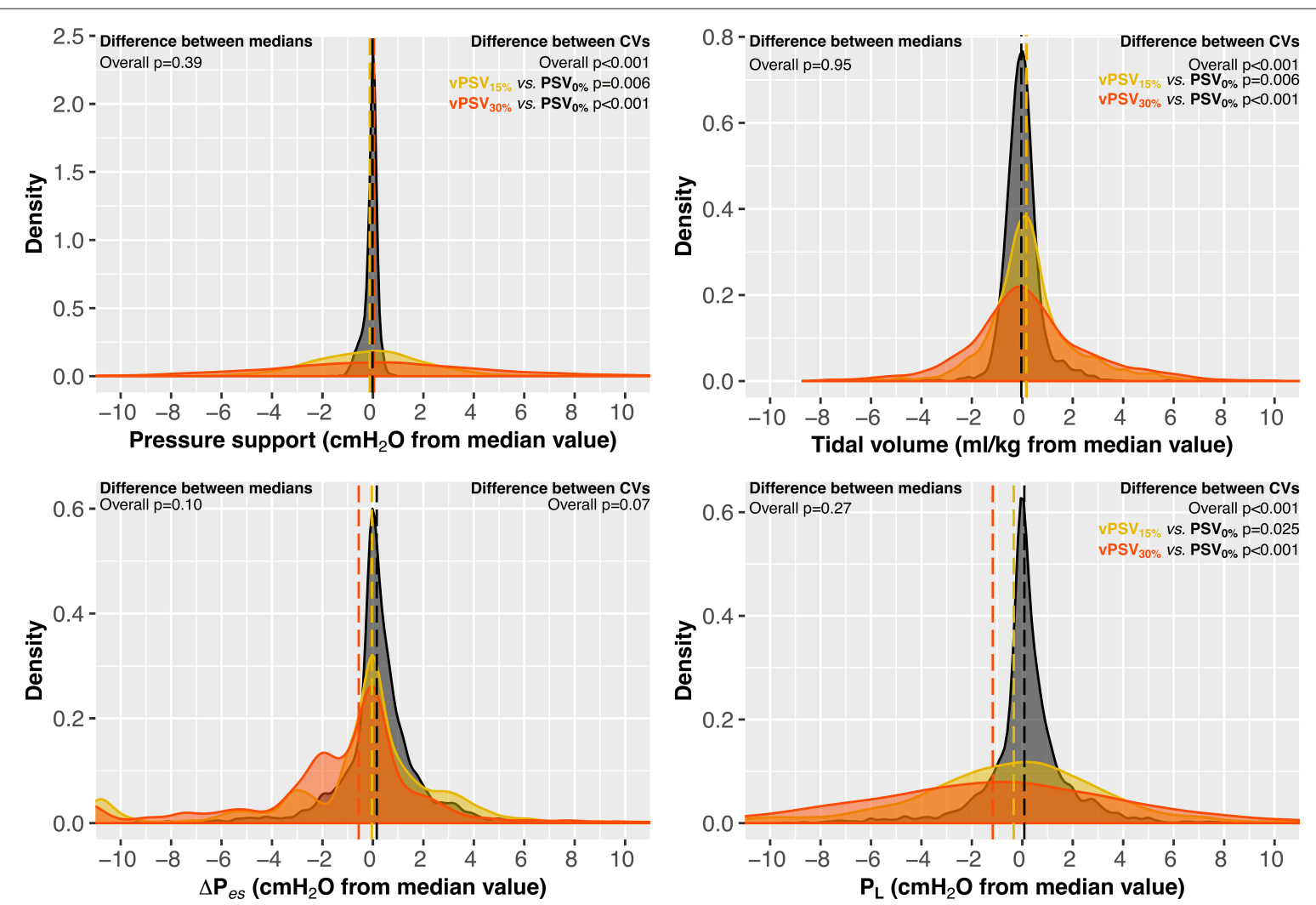

FIGURE 3 | Respiratory mechanics at different levels of variability (block 1). Variables are reported as the difference from the median value achieved during PSV ${ }_{0 \%}$ to allow between-patients visual comparisons. Dashed lines represent the medians of each ventilation step. PSV $0 \%$, conventional PSV ventilation with no variability; vPSV $_{15 \%}$, variable PSV with variability set to $15 \% \mathrm{CV}$; vPSV $30 \%$, variable PSV with variability set to $30 \% \mathrm{CV}$; $\mathrm{CV}$, coefficient of variation; $\Delta P_{\mathrm{S}}$, pressure support; $\Delta P_{\text {es }}$, esophageal pressure swings; $P_{\llcorner}$, peak transpulmonary pressure. 


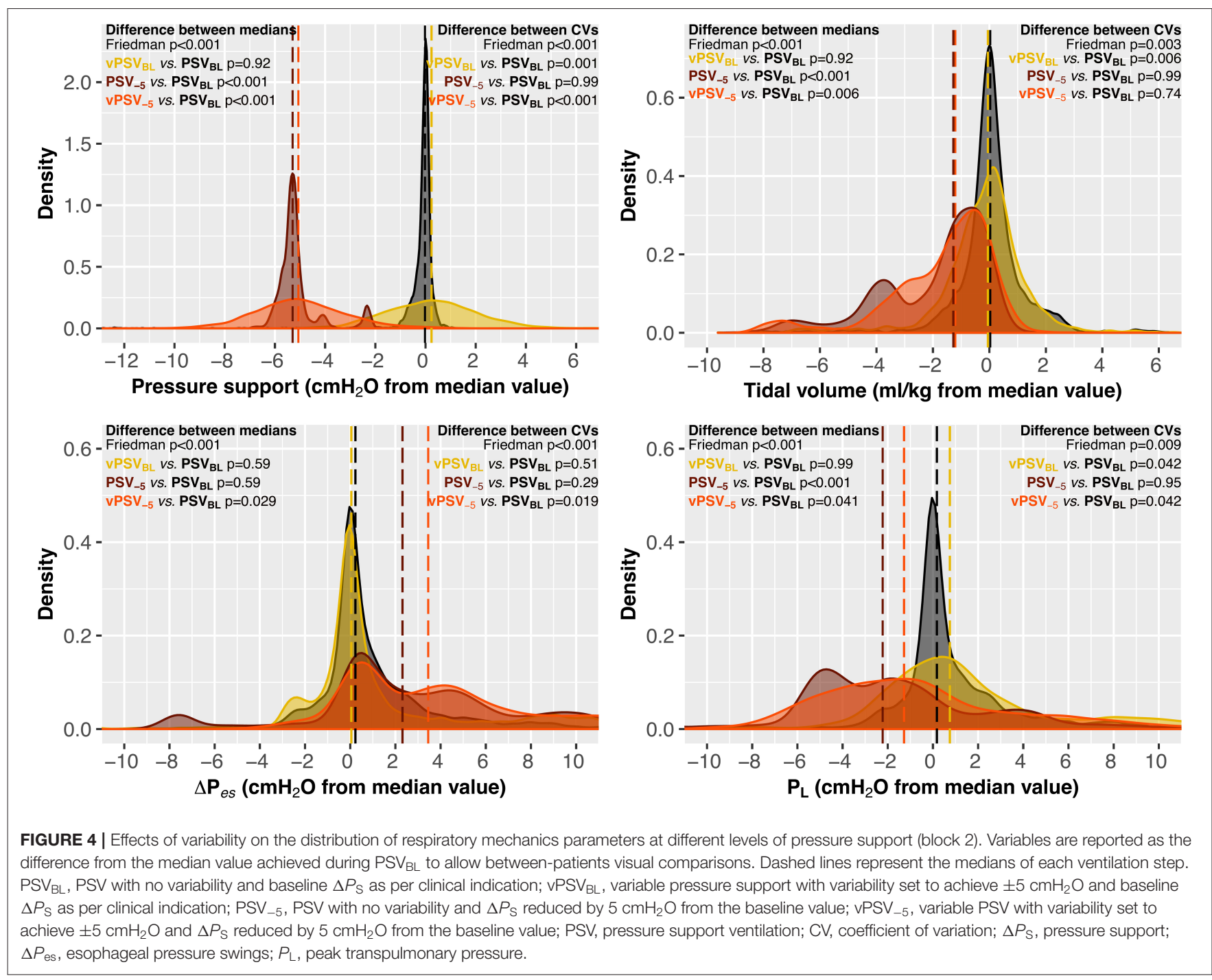

\section{Post-hoc Analysis}

Associations between respiratory mechanics parameters and the pressure level received in the preceding breath during ${ }_{\mathrm{vPSV}} \mathrm{BL}_{\mathrm{BL}}$ and $\mathrm{vPSV}_{-5}$ are reported in Figure 5. The $\Delta P_{\mathrm{S}}$ received in the preceding breath was inversely associated with the magnitude of the inspiratory effort $\left(\triangle P_{\text {es }}\right)$ in the following breath, both during $\operatorname{vPSV}_{\mathrm{BL}}(p=0.003)$ and vPSV $-5(p=0.005)$.

\section{DISCUSSION}

The main findings of this study are that in our mixed-ICU population of patients with mild to moderate ARDS: (1) vPSV with 15 or $30 \%$ variability did not influence gas exchange compared with conventional PSV; (2) at constant $\Delta P_{S}$, vPSV increased the variability of $V_{\mathrm{T}}$ and $P_{\mathrm{L}}$; (3) $\mathrm{vPSV}_{30 \%}$ increased the incidence of asynchronies; and (4) when the $\Delta P_{\mathrm{S}}$ was reduced by $5 \mathrm{cmH}_{2} \mathrm{O}$ from the baseline value, adding variability did not increase the variability of $V_{\mathrm{T}}$ and $P_{\mathrm{L}}$.
This is the first study comparing the short-term effects of vPSV at different levels of variability and $\Delta P_{\mathrm{S}}$ in patients with ARDS. In previous studies, vPSV improved oxygenation in the experimental models of ARDS (Gama de Abreu et al., 2008; Spieth et al., 2011, 2012), but not in a cohort of hypoxemic critically ill patients (Spieth et al., 2013). However, that last study included mostly postoperative patients without a confirmed diagnosis of ARDS and investigated a single level of variability and pressure support. Opposite to what was found in preclinical studies in animals, vPSV had no effect on gas exchange, when the $\Delta P_{\mathrm{S}}$ was set to the baseline value identified by the treating clinician and neither when it was reduced by $5 \mathrm{cmH}_{2} \mathrm{O}$. This could be explained by several mechanisms; most importantly, the time investigated in each ventilation step was relatively short, and the fact that patients had an established diagnosis of ARDS mostly in their recovery phase and received mechanical ventilation for few days prior to the inclusion in this study. Under these conditions, patient lungs could have developed 


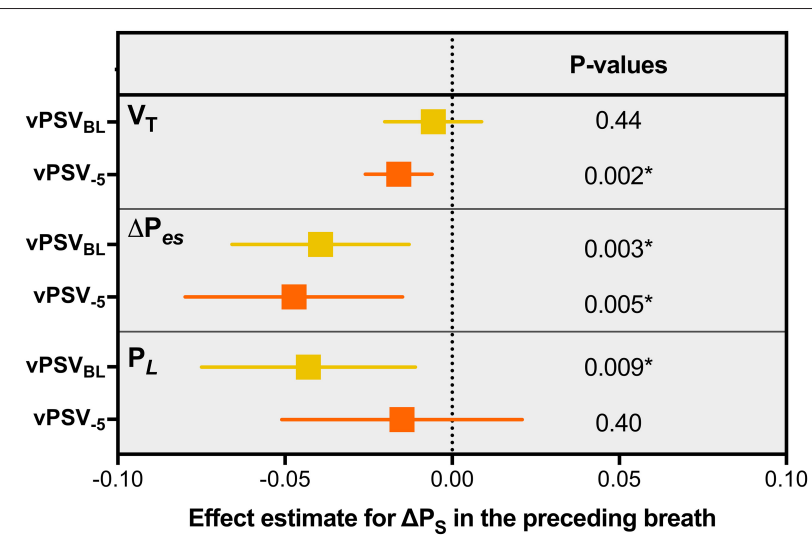

FIGURE 5 | Associations between respiratory mechanics parameters and the pressure level received in the preceding breath during variable PSV. Squares and confidence intervals refer to the effect estimate for $\Delta P_{\mathrm{S}}$ in a mixed model comprising the $\Delta P_{S}$ received during the preceding breath as a fixed effect and the patient as a random effect with random intercept. The units of the estimates are expressed in the untransformed units of the variables, i.e., they represent the absolute change in $V_{\mathrm{T}}, \Delta P_{\mathrm{eS}}$, or $P_{\mathrm{L}}$ when the $\Delta P_{\mathrm{S}}$ received during the preceding breath increases by $1 \mathrm{cmH}_{2} \mathrm{O}$. vPSV $\mathrm{BL}_{\mathrm{BL}}$, variable PSV with variability set to achieve $\pm 5 \mathrm{cmH}_{2} \mathrm{O}$ and baseline $\Delta P_{S}$ as per clinical indication; $v P S V_{-5}$, variable PSV ventilation with variability set to achieve \pm 5 $\mathrm{cmH}_{2} \mathrm{O}$ and $\Delta P_{S}$ reduced by $5 \mathrm{cmH}_{2} \mathrm{O}$ from the baseline value; PBW, predicted body weight; PSV, pressure support ventilation; $\Delta P_{\mathrm{S}}$, pressure support; $V_{\mathrm{T}}$, tidal volume; $\Delta P_{\mathrm{es}}$, esophageal pressure swings; $P_{\mathrm{L}}$, peak transpulmonary pressure. ${ }^{*}$ Significant association $(p<0.05)$.

consolidation, namely, the presence of lung regions scarcely responsive to recruitment (Cressoni et al., 2017). In this case, the breaths with higher $\Delta P_{\mathrm{S}}$ received cyclically during variable pressure support might expose the patient to volutrauma in the aerated regions of the lung (Güldner et al., 2016; Pelosi et al., 2016) due to the reduced size of the lung aerated compartment. Another explanation for the possible lack of effect of variability on oxygenation might be that, different from what happens in PSV with a sigh, vPSV has no control over the time spent at higher pressure during tidal breathing. This might result in random breaths with higher $P_{S}$ and short inspiratory time, both possibly insufficient to achieve recruitment. The tidal volume measured in this cohort was higher than the recommended targets, but this reflects the current clinical practice in patients with ARDS receiving assisted ventilation modes (Bellani et al., 2016; Writing Group for the PReVENT Investigators et al., 2018). During the second block of ventilations, the patients tolerated a $\Delta P_{\mathrm{S}}$ reduction without worsening the gas exchange in the short term, at the price of a modest increase of the respiratory rate, suggesting that they were slightly over-assisted. This could have influenced patient-ventilator interaction (Kataoka et al., 2018) and the response to variability, as suggested by the finding that, during the second block of interventions, the variability of $V_{\mathrm{T}}$ was increased by vPSV compared with PSV only when the baseline $\Delta P_{\mathrm{S}}$ was used. However, during ventilation steps with baseline $\Delta P_{\mathrm{S}}$, patients had a work of breathing estimated with the $\mathrm{PTP}_{\mathrm{es}}$ of around $150 \mathrm{cmH} \mathrm{Cm}_{2} \mathrm{O} \cdot \mathrm{s} \cdot \mathrm{min}^{-1}$, which is within the recommended range (Mauri et al., 2016). Interestingly, higher $P_{\mathrm{S}}$ resulted in a reduction in $\Delta P_{\mathrm{ES}}$ in the following breath at both set $\Delta P_{\mathrm{S}}$ levels, while the variability of $V_{\mathrm{T}}$ and $P_{\mathrm{L}}$ was increased by extrinsic variability only at higher $\Delta P_{\mathrm{S}}$. This seems to suggest that while a neural response to extrinsic variability is present independent of the level of assistance, its effects on the variability of $V_{\mathrm{T}}$ and $P_{\mathrm{L}}$ are influenced by the level of $\Delta P_{\mathrm{S}}$.

This study is underpowered to demonstrate the effects of vPSV on patient-centered outcomes like duration of ventilation. This is tested in another, yet ongoing clinical trial (Kiss et al., 2013). In the post-hoc analysis, the effects of vPSV on the response of patients in terms of inspiratory effort, transpulmonary pressure, and tidal volume developed in the following breath were studied. An inverse association between the $\Delta P_{S}$ received in the preceding breath and the inspiratory effort was observed. Different from other modified PSV modes such as the proportional assist ventilation (PAV) and the neurally adjusted ventilatory assist (NAVA), the variability of $\Delta P_{\mathrm{S}}$ was random, i.e., is not related to the efforts of patients. This analysis suggests that there might be a complex interaction between the ventilator and a patient, in which the inspiratory effort and the adaptation of the patient to pressure support are influenced by the history of the previous breaths.

\section{Limitations}

This study has several limitations. The crossover design allowed the investigation of the effects of different levels of variability and $\Delta P_{\mathrm{S}}$ in terms of gas exchange and respiratory mechanics in the short term but is intrinsically unable to investigate major clinical outcomes. The sample size is relatively low, no static measurements of respiratory mechanics were performed, and patients received heterogeneous sedation regimens that might have affected differently the respiratory drive. The population included in the study identifies a subgroup of critically ill patients meeting the criteria for mild to moderate ARDS who already received controlled or assisted mechanical ventilation for several days; however, the baseline patient characteristics were similar to those reported in a recent large observational study in patients with ARDS assisted noninvasively (Bellani et al., 2017). These patients with established respiratory failure, thus, possibly consolidated lung areas, might not benefit from the cyclic recruitment effect of vPSV, while patients with early ARDS might respond differently. However, the role of spontaneous breathing in the early management of ARDS is still unclear. This study could neither elucidate the mechanisms of the neural responses of the patients to variability nor the neuromuscular coupling of the respiratory muscles.

\section{CONCLUSION}

In our cohort of patients with mild to moderate ARDS, vPSV did not improve gas exchange at different levels of variability and pressure support. Compared with PSV, vPSV increased the variability of $V_{\mathrm{T}}$, but not when low levels of variability were used in conjunction with lower pressure support. Moreover, vPSV did not exert a clinically relevant effect on the average inspiratory effort and work of breathing. 


\section{DATA AVAILABILITY STATEMENT}

The raw data supporting the conclusions of this article will be made available by the authors, without undue reservation.

\section{ETHICS STATEMENT}

The study was approved by the Local Ethical Review Board (Comitato Etico Aziendale Policlinico San Martino protocol no. 1052/12) and prospectively registered on clinicaltrials.gov (study identifier: NCT01683669). According to the local ethical requirements, the next of kin provided written informed assent, followed by delayed written consent from patients in case of recovery of consciousness.

\section{REFERENCES}

Akoumianaki, E., Maggiore, S. M., Valenza, F., Bellani, G., Jubran, A., Loring, S. H., et al. (2014). The application of esophageal pressure measurement in patients with respiratory failure. Am. J. Respir. Crit. Care Med. 189, 520-531. doi: $10.1164 / \mathrm{rccm} .201312-2193 \mathrm{CI}$

Bellani, G., Laffey, J. G., Pham, T., Fan, E., Brochard, L., Esteban, A., et al. (2016). Epidemiology, patterns of care, and mortality for patients with acute respiratory distress syndrome in intensive care units in 50 countries. JAMA 315, 788-800. doi: 10.1001/jama.2016.0291

Bellani, G., Laffey, J. G., Pham, T., Madotto, F., Fan, E., Brochard, L., et al. (2017). Noninvasive ventilation of patients with acute respiratory distress syndrome. Insights from the LUNG SAFE study. Am. J. Respir. Crit. Care Med. 195, 67-77. doi: $10.1164 / \mathrm{rccm} .201606-1306 \mathrm{OC}$

Blanch, L., Villagra, A., Sales, B., Montanya, J., Lucangelo, U., Luján, M., et al. (2015). Asynchronies during mechanical ventilation are associated with mortality. Intensive Care Med. 41, 633-641. doi: 10.1007/s00134-015-3692-6

Cressoni, M., Chiumello, D., Algieri, I., Brioni, M., Chiurazzi, C., Colombo, A., et al. (2017). Opening pressures and atelectrauma in acute respiratory distress syndrome. Intensive Care Med. 43, 603-611. doi: 10.1007/s00134-0174754-8

Esteban, A., Frutos-Vivar, F., Muriel, A., Ferguson, N. D., Peñuelas, O., Abraira, V., et al. (2013). Evolution of mortality over time in patients receiving mechanical ventilation. Am. J. Respir. Crit. Care Med. 188, 220-230. doi: 10.1164/rccm.201212-2169OC

Gama de Abreu, M., Spieth, P. M., Pelosi, P., Carvalho, A. R., Walter, C., SchreiberFerstl, A., et al. (2008). Noisy pressure support ventilation: a pilot study on a new assisted ventilation mode in experimental lung injury. Crit. Care Med. 36, 818-827. doi: 10.1097/01.CCM.0000299736.55039.3A

Güldner, A., Braune, A., Ball, L., Silva, P. L., Samary, C., Insorsi, A., et al. (2016). Comparative effects of volutrauma and atelectrauma on lung inflammation in experimental acute respiratory distress syndrome. Crit. Care Med. doi: 10.1097/CCM.0000000000001721

Huhle, R., Pelosi, P., and de Abreu, M. G. (2016). Variable ventilation from bench to bedside. Crit. Care Lond. Engl. 20:62. doi: 10.1186/s13054-016-1216-6

Kataoka, J., Kuriyama, A., Norisue, Y., and Fujitani, S. (2018). Proportional modes versus pressure support ventilation: a systematic review and meta-analysis. Ann. Intensive Care 8:123. doi: 10.1186/s13613-0180470-y

Kiss, T., Güldner, A., Bluth, T., Uhlig, C., Spieth, P. M., Markstaller, K., et al. (2013). Rationale and study design of ViPS - variable pressure support for weaning from mechanical ventilation: study protocol for an international multicenter randomized controlled open trial. Trials 14:363. doi: $10.1186 / 1745-6215-14-363$

\section{AUTHOR CONTRIBUTIONS}

LB takes responsibility for the integrity of data. LB, PP, MV, and MG designed the study. LB, YS, MF, AD'O, DD'A, PRa, and IB conducted the study. LB, LM, MF, RH, AD'O, and CR analyzed the data. LB, MS, PP, PRo, and MG wrote the manuscript. All authors read and approved the final version of the manuscript.

\section{FUNDING}

This study was performed with institutional funding only.

\section{SUPPLEMENTARY MATERIAL}

The Supplementary Material for this article can be found online at: https://www.frontiersin.org/articles/10.3389/fphys. 2021.725738/full\#supplementary-material

Mauri, T., Lazzeri, M., Bronco, A., Bellani, G., and Pesenti, A. (2017). Effects of variable pressure support ventilation on regional homogeneity and aeration. Am. J. Respir. Crit. Care Med. 195, e27-e28. doi: 10.1164/rccm.201609-1806IM

Mauri, T., Yoshida, T., Bellani, G., Goligher, E. C., Carteaux, G., Rittayamai, N., et al. (2016). Esophageal and transpulmonary pressure in the clinical setting: meaning, usefulness and perspectives. Intensive Care Med. 42, 1360-1373. doi: $10.1007 / \mathrm{s} 00134-016-4400-x$

Muller, K. E., and Barton, C. N. (1989). Approximate power for repeatedmeasures ANOVA lacking sphericity. J. Am. Stat. Assoc. 84, 549-555. doi: 10.1080/01621459.1989.10478802

Muller, K. E., Lavange, L. M., Ramey, S. L., and Ramey, C. T. (1992). Power calculations for general linear multivariate models including repeated measures applications. J. Am. Stat. Assoc. 87, 1209-1226. doi: 10.1080/01621459.1992.10476281

Pelosi, P., Ball, L., Abreu, M. G., de, and Rocco, P. R. M. (2016). General anesthesia closes the lungs: keep them resting. Turk. J. Anesth. Reanim. 44, 163-164. doi: 10.5152/TJAR.2016.002

Putensen, C., Zech, S., Wrigge, H., Zinserling, J., Stüber, F., Von Spiegel, T., et al. (2001). Long-term effects of spontaneous breathing during ventilatory support in patients with acute lung injury. Am. J. Respir. Crit. Care Med. 164, 43-49. doi: 10.1164/ajrccm.164.1.2001078

Spieth, P. M., Carvalho, A. R., Güldner, A., Kasper, M., Schubert, R., Carvalho, N. C., et al. (2011). Pressure support improves oxygenation and lung protection compared to pressure-controlled ventilation and is further improved by random variation of pressure support. Crit. Care Med. 39, 746-755. doi: 10.1097/CCM.0b013e318206bda6

Spieth, P. M., Güldner, A., Beda, A., Carvalho, N., Nowack, T., Krause, A., et al. (2012). Comparative effects of proportional assist and variable pressure support ventilation on lung function and damage in experimental lung injury. Crit. Care Med. 40, 2654-2661. doi: 10.1097/CCM.0b013e31825 92021

Spieth, P. M., Güldner, A., Huhle, R., Beda, A., Bluth, T., Schreiter, D., et al. (2013). Short-term effects of noisy pressure support ventilation in patients with acute hypoxemic respiratory failure. Crit. Care Lond. Engl. 17:R261. doi: 10.1186/cc13091

Tobin, M. J., Mador, M. J., Guenther, S. M., Lodato, R. F., and Sackner, M. A. (1988). Variability of resting respiratory drive and timing in healthy subjects. J. Appl. Physiol. (1985) 65, 309-317. doi: 10.1152/jappl.1988.65. 1.309

Writing Group for the PReVENT Investigators, Simonis, F. D., Serpa Neto, A., Binnekade, J. M., Braber, A., Bruin, K. C. M., et al. (2018). Effect of a low vs intermediate tidal volume strategy on ventilator-free days in intensive care unit patients without ARDS: a randomized clinical trial. JAMA 320, 1872-1880. doi: 10.1001/jama.2018.14280 
Conflict of Interest: MG was granted a patent on the variable pressure support ventilation mode of assisted ventilation (noisy PSV), which has been licensed to Dräger Medical AG (Lübeck, Germany).

The remaining authors declare that the research was conducted in the absence of any commercial or financial relationships that could be construed as a potential conflict of interest.

Publisher's Note: All claims expressed in this article are solely those of the authors and do not necessarily represent those of their affiliated organizations, or those of the publisher, the editors and the reviewers. Any product that may be evaluated in this article, or claim that may be made by its manufacturer, is not guaranteed or endorsed by the publisher.

Copyright (๑) 2021 Ball, Sutherasan, Fiorito, Dall'Orto, Maiello, Vargas, Robba, Brunetti, D'Antini, Raimondo, Huhle, Schultz, Rocco, Gama de Abreu and Pelosi. This is an open-access article distributed under the terms of the Creative Commons Attribution License (CC BY). The use, distribution or reproduction in other forums is permitted, provided the original author(s) and the copyright owner(s) are credited and that the original publication in this journal is cited, in accordance with accepted academic practice. No use, distribution or reproduction is permitted which does not comply with these terms. 